\title{
Valproate inhibits colon cancer growth through cell cycle modification in vivo and in vitro
}

\author{
CHRISTOPH W. STREY ${ }^{1}$, LEA SCHAMELL ${ }^{1}$, ELSIE OPPERMANN ${ }^{1}$, \\ AXEL HAFERKAMP $^{2}$, WOLF O. BECHSTEIN ${ }^{1}$ and ROMAN A. BLAHETA ${ }^{2}$ \\ Departments of ${ }^{1}$ General and Visceral Surgery, and ${ }^{2}$ Urology, \\ Johann Wolfgang Goethe-University Frankfurt, 60590 Frankfurt am Main, Germany
}

Received October 13, 2010; Accepted December 30, 2010

DOI: $10.3892 /$ etm.2011.202

\begin{abstract}
Valproate (VPA) is a well-characterized histone deacetylase inhibitor with anti-neoplastic properties. We analyzed the growth blocking effects and the molecular mode of action of this compound in colorectal cancer cells in vitro and in vivo. Caco-2, SW-480, CX-1 or WIDR cell lines were exposed to VPA (0.25-2 mM) for various time periods. Cell growth, cell cycle progression and apoptosis were analyzed by 3-(4,5dimethylthiazol-2-yl)-2,5-diphenyl-tetrazolium bromide dye reduction assay and flow cytometry. Cell cycle- and apoptosisregulating proteins and histone acetylation were assessed by Western blotting. In vivo tumor growth and regulating protein expression under VPA were investigated in a subcutaneous xenograft tumor model. VPA inhibited the growth of all cell lines with cell cycle arrest paralleled by the up-regulation of $\mathrm{H} 3$ and $\mathrm{H} 4$ acetylation. In vivo tumor growth was substantially depressed by VPA (200 mg/kg bw). Cell cycle proteins (cdk1, cdk2, cdk4, cyclin D, cyclin E, p19, p21 and p27) were differentially altered by VPA. Predominantly cdk1 was decreased and p27 was up-regulated in all models. Apoptosis-related proteins were altered in vivo with up-regulation of bax and down-regulation of bcl-2. VPA exerts anti-neoplastic activity in colorectal tumor cell lines in vitro and in vivo by altering cell cycle regulation.
\end{abstract}

\section{Introduction}

Neoplastic cell proliferation and inhibition of cell death is maintained by aberrant gene expression. Histone deacetylase (HDAC) inhibitors offer a means to modulate these genetic changes by influencing the status of the epigenome (1). Valproate (VPA), an established HDAC inhibitor for the

Correspondence to: Dr Christoph W. Strey, Department of General and Visceral Surgery, Johann Wolfgang Goethe-University Frankfurt, Theodor-Stern-Kai 7, 60590 Frankfurt am Main, Germany

E-mail: strey@gmx.de

Key words: valproic acid, tumor cell lines, histone deacetylase inhibition, colorectal cancer treatment of epilepsy with advantageous pharmacokinetic properties, causes hyperacetylation of the N-terminal tails of histones $\mathrm{H} 3$ and $\mathrm{H} 4$ in vitro and in vivo (2). Thereby, VPA directly inhibits HDAC enzymatic activity at concentrations of approximately $0.5 \mathrm{mM}(3)$.

The associated antitumor effect of VPA is conveyed by modulating multiple pathways, including cell cycle, apoptosis, angiogenesis, metastasis, differentiation and senescence. These effects depend in part on the level of differentiation and the associated underlying genetic alterations which differ between tumor entities. This could explain why VPA does not show homogenous responses in all malignant cell types. The majority of clinical data on the antitumor effects of VPA have been generated in the context of malignant hematological diseases (4). Solid tumors have recently been added to the circle of malignancies whose growth and survival may be influenced by VPA (5), which is currently in clinical trials (6). Information on the activity of VPA and other HDAC inhibitors against colon cancer is limited and inconsistent among cell lines (7). For example, the VPA effect has been shown to partially depend on the expression of wild-type adenomatous polyposis coli (APC) protein in colon cancer cell lines, whereas mutant APC-expressing cells showed decreased VPA sensitivity (8). Additionally, the response of freshly isolated primary colon cancer cells to VPA treatment showed interindividual variations (9).

To clarify the extent and variability of VPA activity concerning colon cancer cell growth, the in vitro response of four colon cancer cell lines (Caco-2, SW-480, CX-1 and WIDR) to VPA exposure was investigated. Furthermore, SW-480 cells were implanted into NOD/SCID mice to compare the in vitro findings with the anti-neoplastic effect of VPA in vivo.

\section{Materials and methods}

Cell cultures. Human colon cancer cell lines (Caco-2, SW-480, CX-1 and WIDR) were obtained from DSMZ (Braunschweig, Germany). Caco-2, CX-1 and WIDR cells were cultured in Earles' minimum essential medium (MEM), and SW-480 cells were cultured in McCoy's 5A medium (Gibco/Invitrogen, Kalsruhe, Germany), supplemented with $10 \%$ fetal calf serum (FCS), 20 mM HEPES-buffer (pH 7.4), 2\% glutamine and 1\% 
penicillin/streptomycin. Subcultures from passages 7-11 were selected for experimental use.

Drugs. VPA (a gift from G.L. Pharma GmbH, Lannach, Austria) was used at a final concentration of $0.25,0.5,1$ or $2 \mathrm{mM}$. The tumor cells were treated with VPA for 3 or 5 days. The controls remained untreated. To exclude the toxic effects of the compounds, cell viability was determined by trypan blue (Gibco/Invitrogen).

Detection of apoptosis. To detect apoptosis, the expression of Annexin V/propidium iodide (PI) was evaluated using the Annexin V-FITC Apoptosis Detection kit (BD Pharmingen, Heidelberg, Germany). Staining was performed according to the manufacturer's instructions. Briefly, tumor cells were dislodged with accutase (PAA Laboratories $\mathrm{GmbH}$, Coelbe, Germany), washed once with cold PBS and resuspended in $1 \mathrm{X}$ binding buffer $\left(1 \times 10^{6}\right.$ cells $\left./ \mathrm{ml}\right)$. The cell suspension $(100 \mu \mathrm{l}$; $1 \times 10^{5}$ cells) was then incubated with $5 \mu \mathrm{l}$ of Annexin V-FITC and $5 \mu \mathrm{l}$ of PI in the dark for $15 \mathrm{~min}$ at room temperature. The cells were analyzed on a FACScalibur (BD Biosciences, Heidelberg, Germany). The percentage of apoptotic cells (early and late) in each quadrant was calculated using CellQuest software (BD Biosciences).

Measurement of tumor cell growth. Cell growth was assessed using the 3-(4,5-dimethylthiazol-2-yl)-2,5-diphenyltetrazolium bromide (MTT) dye reduction assay (Roche Diagnostics, Penzberg, Germany). Treated vs. non-treated tumor cells (100 $\mu \mathrm{l} ; 1 \times 10^{4}$ cells $\left./ \mathrm{ml}\right)$ were seeded into 96-well culture plates. After 24, 48 and $72 \mathrm{~h}$, MTT $(0.5 \mathrm{mg} / \mathrm{ml})$ was added to the cells and incubated for $4 \mathrm{~h}$ at $37^{\circ} \mathrm{C}$ in $5 \% \mathrm{CO}_{2}$. Thereafter, solubilization buffer containing $10 \%$ SDS in $0.01 \mathrm{M} \mathrm{HCl}$ was added to dissolve the purple formazan salt crystals by allowing the plate to stand overnight at $37^{\circ} \mathrm{C}$ in $5 \% \mathrm{CO}_{2}$. The absorbance of the solubilized purple formazan product was spectrophotometrically measured at $570 \mathrm{~nm}$ using Infinite ${ }^{\circledR}$ M 200 microplate reader (Tecan-Deutschland, Crailsheim, Germany). Each experiment was carried out in triplicate. After subtracting the background absorbance, the results were expressed as the mean cell number.

Cell cycle analysis. Tumor cells were grown to $70 \%$ confluency and subsequently treated with VPA (controls remained untreated). After $24 \mathrm{~h}$, tumor cell populations were stained according to the manufacturer's instruction using a Cycle Test Plus DNA Reagent kit (Becton Dickinson) and subsequently analyzed by a FACScan flow cytometer (Becton Dickinson). Events $(10,000)$ were collected from each sample. Data acquisition was carried out using CellQuest software, and the cell cycle distribution was calculated using ModFit software (Becton Dickinson). The number of gated cells in G1, G2/M or S-phase was presented as a percentage.

Western blot analysis. To explore cell cycle-regulating proteins, tumor cell lysates were subjected to sodium dodecyl sulfate polyacrylamide gel electrophoresis (SDS-PAGE; $50 \mu \mathrm{g}$ per lane). PeqGold pre-stained protein marker IV (Peqlab Biotechnologie GmbH, Erlangen, Germany) was used as a molecular weight standard. Following separation, protein was transferred to a polyvinyl difluoride membrane (PVDF; Hybond P; GE Healthcare, Munich, Germany). The blots were blocked with $10 \%$ low-fat milk for $1 \mathrm{~h}$ at room temperature, followed by incubation overnight at $4^{\circ} \mathrm{C}$ with monoclonal antibodies directed against cell cycle proteins: Cdk1 (IgG1, clone 1, 1:2,000), cdk2 (IgG2a, clone 55, 1:2,000), cdk4 (IgG1, clone 97, 1:250), cyclin D1 (IgG1, clone G124-326, 1:500), cyclin E (IgG1, clone HE12, 1:2,000), p19 (IgG1, clone 52, 1:5,000), p21 (IgG1, clone 2G12, 1:200) and p27 (IgG1, clone 57, 1:200) (all antibodies from BD Biosciences). Apoptosis was analyzed using bax (IgG1, clone 3, 1:250) and bcl-2 (IgG1, clone 7/bcl-2, 1:500) antibodies from BD Transduction Laboratories (Heidelberg, Germany). Antihistone H3 (IgG, clone Y173, 1:5,000), anti-acetylated H3 (IgG, clone Y28, 1:500), anti-histone H4 (polyclonal IgG, 1:250) and anti-acetylated H4 (Lys8, polyclonal IgG, 1:500) were all from Biomol GmbH (Hamburg, Germany). HRP-conjugated goat anti-mouse IgG (1:5,000; Millipore GmbH, Schwalbach/Ts, Germany) served as the secondary antibody. $\beta$-actin $(1: 1,000$; Sigma, Taufenkirchen, Germany) served as a loading control. The antibodies were diluted in Towbin buffer with $0.5 \%$ Tween-20 and $0.5 \%$ bovine serum albumin. The membranes were briefly incubated with ECL detection reagent (Enhanced Chemiluminescence-ECL ${ }^{\mathrm{TM}}$; GE Healthcare) and exposed to ECL Hyperfilm (GE Healthcare) developed in Curix 60 (Agfa, Dusseldorf, Germany) and documented by Gel Doc (BioRad Laboratories GmbH, Munich, Germany).

Tumor growth in vivo. In vivo experiments were carried out ethically by EPO-Experimental Pharmacology \& Oncology $\mathrm{GmbH}$ (Berlin, Germany). SW-480 cells $\left(1 \times 10^{7}\right)$ were injected subcutaneously into female NOD/SCID mice. Treatment was initiated when the tumors had grown to a palpable size (5-6 $\mathrm{mm}$ diameter). VPA was dissolved in saline, and the mice were treated intraperitoneally with single doses of 100 , 200 and $300 \mathrm{mg} / \mathrm{kg}$ bw VPA once daily $(\mathrm{n}=10)$. The control mice received normal saline. Each amount of VPA was well-tolerated, and the experiment was terminated on day 25. Tumor size was measured using a vernier caliper. Body weight and mortality were recorded continuously to estimate tolerability. The tumor tissue was excised to evaluate protein expression by Western blot analysis.

Statistics. The experiments were performed 3-6 times. Statistical significance was calculated by the Wilcoxon MannWhitney U-test. Differences were considered statistically significant at a p-value of $<0.05$.

\section{Results}

Diminished tumor cell proliferation under valproate exposure in vitro. VPA significantly blocked the growth of the cell lines investigated (Fig. 1). No differences were noted between 3 and 5 days of pre-treatment. Therefore, only the results after a 5-day VPA exposure are shown. Nevertheless, the efficacy of VPA to diminish tumor growth depended on the cell line used. WIDR cells responded weakly to VPA. Application of $2 \mathrm{mM}$ VPA was required to distinctly down-regulate WIDR cell growth. By contrast, $0.5 \mathrm{mM}$ VPA was sufficient to stop the cell growth of Caco-2 cells, and the growth dynamics 

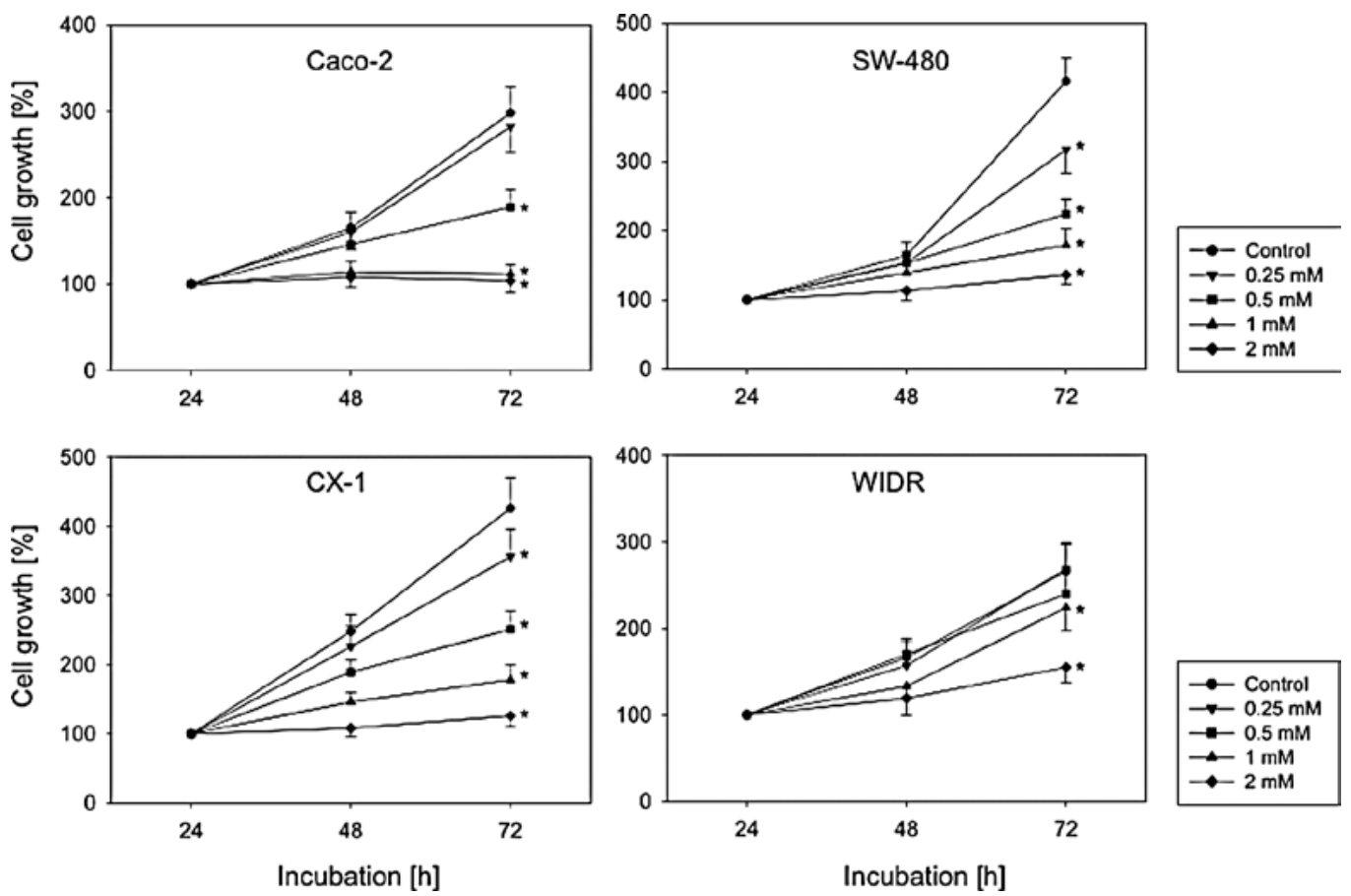

Figure 1. Cell growth of four colon cancer cell lines (Caco-2, SW-480, CX-1 and WIDR) after 5 days of pre-treatment with various valproate concentrations $(0.25,0.5,1.0$ and $2.0 \mathrm{mM})$ are compared to untreated controls. Proliferation was determined (MTT dye reduction assay) after 24, 48 and $72 \mathrm{~h}$, while the $24-\mathrm{h}$ time point served as reference. " $\mathrm{p}<0.05$ vs. control.

of CX-1 and SW-480 were altered even at concentrations of $0.25 \mathrm{mM}$ VPA (Fig. 1).

Valproate exposure increases histone deacetylase-3 and -4 acetylation. As VPA is an inhibitor of histone deacetylase, this experiment aimed to prove that this property also holds true for the colorectal cell lines investigated. Therefore, acetylation was analyzed by Western blotting. The four cell lines showed a dose-dependent increase in $\mathrm{H} 3$ and $\mathrm{H} 4$ acetylation under the influence of VPA, while the amount of histone proteins did not change (Fig. 2).

Valproate alters the proportion of cells in different cell cycle phases. A major finding in cell cultures under anti-neoplastic treatment is the shift of cell cycle phases. This effect has also previously been shown for VPA (5). Therefore, the proportion of the colorectal cancer cell lines undergoing various cell cycle phases under VPA exposure was determined. The four cell lines displayed a concentration-dependent cell cycle shift towards the G0/G1 phase and a corresponding reduction in S-phase cells (Fig. 3). The strongest alterations were induced in Caco-2, CX-1 and SW-480 cells, whereas WIDR responded only poorly to the drug treatment.

Valproate alters key cell cycle-regulating proteins. Subsequent experiments concentrated on the mechanistic background responsible for the cell growth blockade. Fig. 4 shows that the expression of regulatory proteins was altered differentially by VPA among the cell lines investigated. A distinct cell cycle protein response was noted in the Caco-2 cells. Here, the expression of cdk1, 2 and 4 as well as cyclin D1 and E was reduced in a dose-dependent manner (Fig. 4A). By contrast, SW-480 (Fig. 4B) displayed a clear reduction in expression

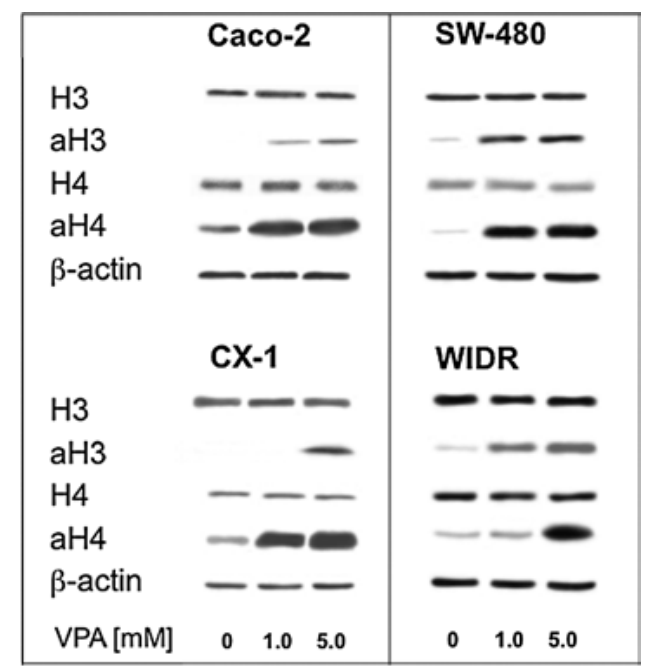

Figure 2. Western blot analysis of histone deacetylase-3 and -4 and the corresponding acetylated fractions (aH3 and $\mathrm{aH} 4)$ of protein extracts from Caco-2, SW-480, CX-1 and WIDR cell cultures treated with valproate (VPA) (1 or $5 \mathrm{mM}$ ). The cells were lysed and probed with the corresponding antibodies, while $\beta$-actin served as an internal control (one out of three experiments is shown).

for cdk1. CX-1 cells (Fig. 4C) came closest to the Caco-2 pattern revealed by the loss of expression of cdk1, 2 and 4 as well as cyclin D1, while the expression of cyclin E increased under VPA. WIDR cells (Fig. 4D) showed a reduction in cdk1 with a more pronounced expression of cdk 4 and cyclin D1. Additionally, Western blot analysis was performed for three tumor-suppressor proteins. P19 was strongly up-regulated in the SW-480 cells and moderately enhanced in the Caco-2 cells. No alterations were induced in the CX-1 and WIDR cells. P21 was not detectable in the SW-480 cells, but a significant increase 

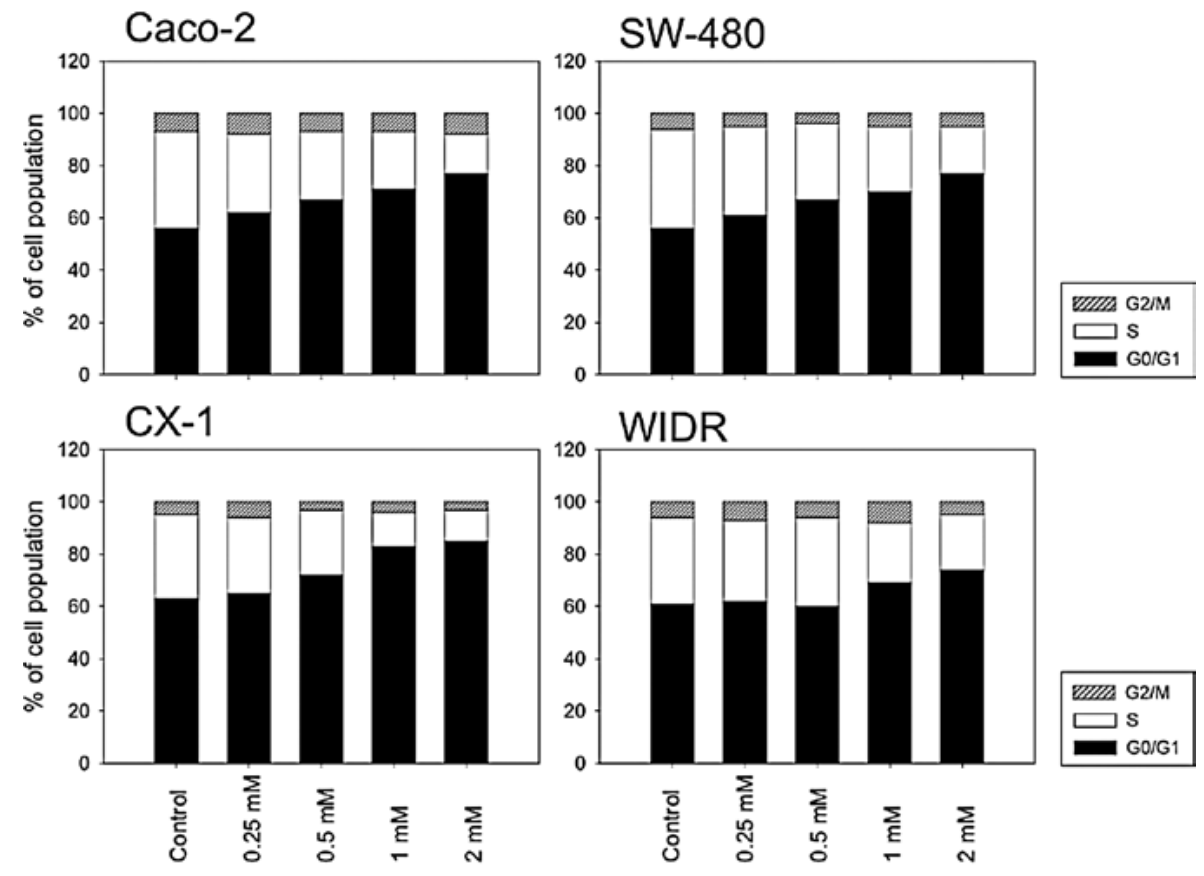

Figure 3. Cell cycle analysis of Caco-2, SW-480, CX-1 and WIDR cell lines after 5 days of valproate exposure $(0.25,0.5,1.0$ and $2.0 \mathrm{mM})$ revealed a clear dose-dependent reduction of cells entering the $\mathrm{S}$ phase in the four cell lines.

\begin{tabular}{|c|c|c|}
\hline $\mathbf{A}$ & Caco-2 & SW-480 \\
\hline $\begin{array}{l}\text { cdk1 } \\
\text { cdk2 } \\
\text { cdk4 } \\
\text { cyclin D1 } \\
\text { cyclin E }\end{array}$ & $\begin{array}{l}\text { ஃニニニニ } \\
\text { ニニニ- } \\
\text {-ーー }\end{array}$ & $\begin{array}{l}\text { ニニニニニ } \\
\text { ニニーニニ } \\
\text { ニニニニニ }\end{array}$ \\
\hline $\begin{array}{l}\text { 199 } \\
\text { p21 } \\
\text { p27 }\end{array}$ & $\underset{\text { n.d. }}{---a}$ & $-\frac{-}{\text { n.d. }}-0$ \\
\hline$\beta$-actin & $-\cdots-\cdots$ & ----- \\
\hline VPA [mM] & C 0.250 .512 & C 0.250 .5112 \\
\hline $\mathrm{C}$ & CX-1 & D $\quad$ WIDR \\
\hline $\begin{array}{l}\text { cdk1 } \\
\text { cdk2 } \\
\text { cdk4 } \\
\text { cyclin D1 } \\
\text { cyclin E }\end{array}$ & 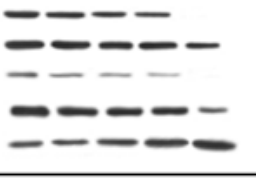 & 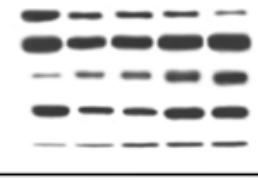 \\
\hline $\begin{array}{l}\text { p19 } \\
\text { p21 } \\
\text { p27 }\end{array}$ & -ニニ=- & $\begin{array}{l}000 \\
--10-0\end{array}$ \\
\hline$\beta$-actin & $----\div$ & $-\infty-0-$ \\
\hline VPA [mM] & 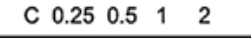 & $\begin{array}{llll}\text { C } 0.25 & 0.5 & 1 & 2 \\
\end{array}$ \\
\hline
\end{tabular}

Figure 4. Western blot analysis of major cell cycle-regulating proteins. Caco-2 (A), SW-480 (B), CX-1 (C) and WIDR (D) cell lines were treated with increasing concentrations of valproate (VPA) over 5 days $(0.25,0.5$, 1.0 and $2.0 \mathrm{mM}$ ) and subsequently analyzed. Representative results of three independent experiments are shown. $\beta$-actin served as an internal control.

over the control cell cultures was noted in the WIDR, CX-1 and Caco- 2 cells. P27 was profoundly elevated in the SW-480 and CX-1 cells and, to a lesser extent, in the WIDR cells. P27 was not detectable in the Caco-2 control cells (Fig. 4).
Valproate exposure enhances apoptosis. The presence of apoptotic events was analyzed and the alterations of the corresponding key proteins bax and bcl-2 was evaluated. The proportion of apoptotic Caco-2 cells did not change in a prominent manner under VPA treatment. However, CX-1 and SW-480 cells showed a significant increase in the cell proportion with features of early ( $2 \mathrm{mM} \mathrm{VPA}$ ) and late apoptosis $(1+2$ mM VPA; represented by CX-1; Fig. 5A and B, upper panel). Elevated amounts of apoptotic cells were also detected with respect to WIDR cells following treatment with $2 \mathrm{mM}$ VPA (Fig. 5B, lower panel). Western blot analysis of bax and bcl-2 expression revealed a dose-dependent decrease in bcl-2, particularly in CX-1 cells, whereas bax was only slightly enhanced in WIDR cells with $2 \mathrm{mM}$ VPA exposure (Fig. 5C).

Valproate treatment suppresses colon cancer growth in vivo. To confirm the in vitro findings in an in vivo model, tumor xenografts were established in NOD/SCID mice using the SW-480 cell line. VPA applied at a $200 \mathrm{mg} / \mathrm{kg}$ dosage significantly inhibited tumor growth as measured by tumor volume (Fig. 6A). At day 21, the tumor volume was calculated to be $0.51 \pm 0.17 \mathrm{~cm}^{3}$ (VPA) vs. $0.89 \pm 0.25 \mathrm{~cm}^{3}$ (control). Notably, a VPA dose of $300 \mathrm{mg} / \mathrm{kg}$ was less effective compared to the $200 \mathrm{mg} / \mathrm{kg}$ schedule. Tumors showed a growth pattern recovery at day 25 in the presence of VPA, but remained significantly smaller than tumors taken from untreated animals.

Valproate treatment changes histone acetylation, cell cycleand apoptosis-related proteins in vivo. In analogy to the in vitro experiments, histone acetylation, cell cycle-regulating and apoptosis-related proteins were analyzed. VPA treatment resulted in an increase in acetylated $\mathrm{H} 3$ and $\mathrm{H} 4$ in a dosedependent manner with a plateau phase at $200 \mathrm{mg} / \mathrm{kg}$ (Fig. 6B). 


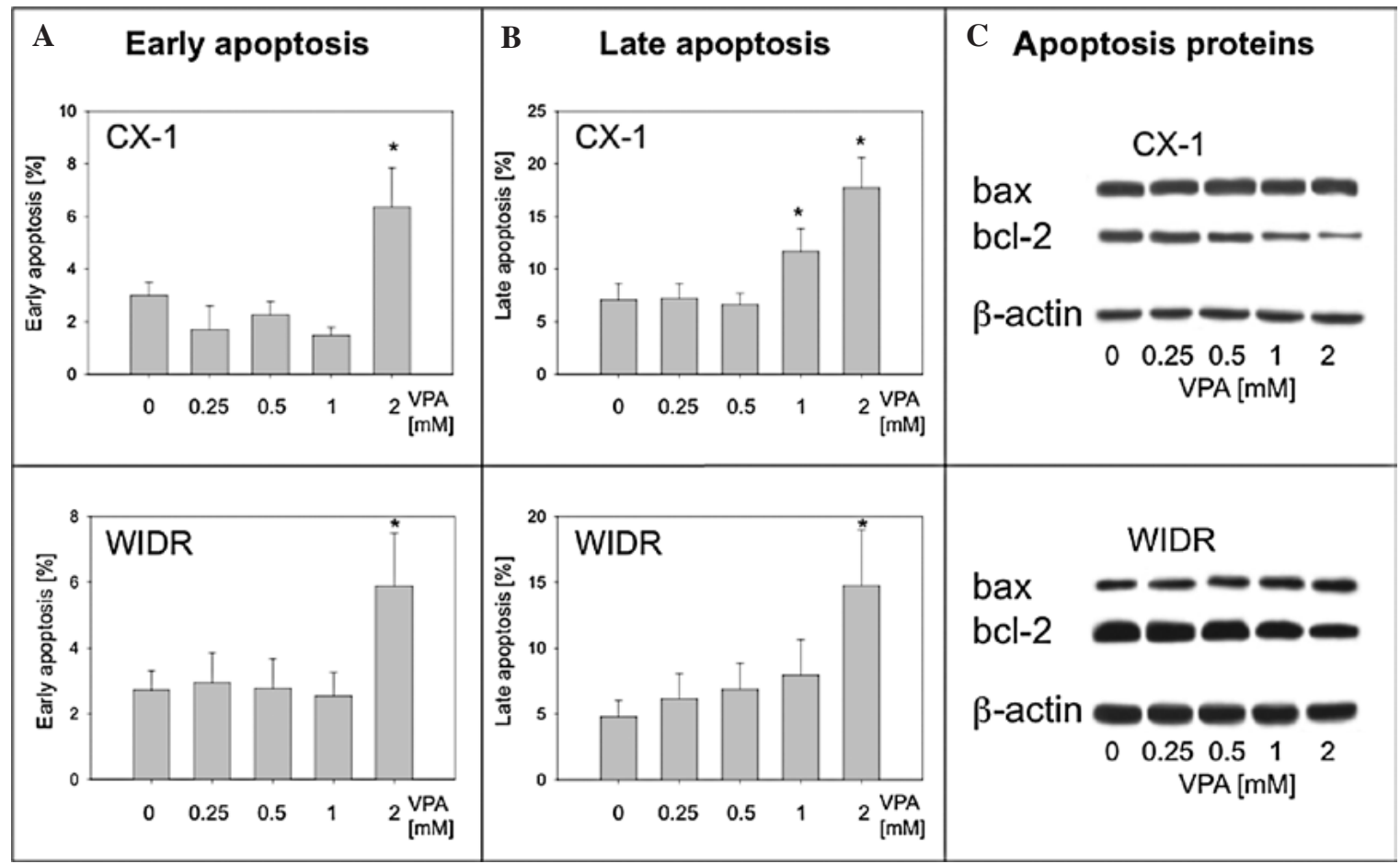

Figure 5. The presence of apoptosis was analyzed in the cell cultures after a 5-day period of valproate (VPA) exposure with the Annexin V FACS assay. The percentage of (A) early and (B) late apoptotic signs for CX-1 (upper panel) and WIDR (lower panel) cultures is shown. The proportion of cells undergoing apoptotic alterations increased significantly under VPA treatment. The maximum response was found with $2 \mathrm{mM}$ VPA when compared to the untreated controls. (C) From the cell cultures, the corresponding protein extracts were also analyzed for apoptosis-related proteins (bax and bcl-2) . $\beta$-actin served as an internal control.

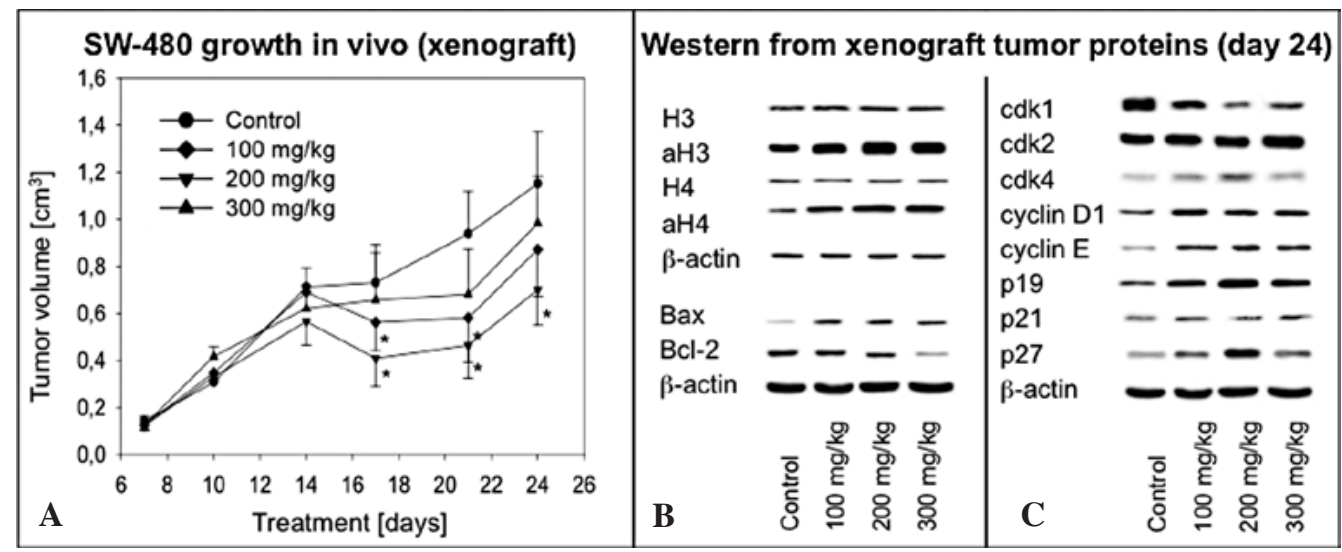

Figure 6. (A) Treatment of male SCID mice with subcutaneous SW-480 xenografts with increasing doses of valproate (VPA) (100, $200 \mathrm{and} 300 \mathrm{mg} / \mathrm{kg}$ bw) resulted in a significant reduction in tumor volume beginning 17 days after treatment until 24 days, compared to the control (solvent treatment) . A maximum and significant growth reduction was noted with $200 \mathrm{mg} / \mathrm{kg}$ VPA. (B) Tissue samples were analyzed for $\mathrm{H} 3$ and $\mathrm{H} 4$ expression and their corresponding acetylation, aH3 and aH4. (C) Histone acetylation increased with VPA treatment with a maximum response at $200 \mathrm{mg} / \mathrm{kg}$. Cdk1, 2 and 4, cyclin D1 and E as well as tumor suppressors p19, p21 and p27 expression under the influence of 100, 200 and $300 \mathrm{mg} / \mathrm{kg}$ VPA. Results from one representative experiment out of three are shown.

Cdk1 expression was reduced, whereas cdk4 increased with maximum effects noted at $200 \mathrm{mg} / \mathrm{kg}$ VPA (Fig. 6C). Cyclin D1 and E expression was more prominent under VPA treatment when compared to the control, although no dosedependent effects were observed. Notably, p19 and p27 were considerably elevated with a maximum response at $200 \mathrm{mg} / \mathrm{kg}$ VPA. Finally, VPA treatment resulted in an increase in the pro-apoptotic protein bax and a decrease in the anti-apoptotic protein bcl-2 (Fig. 6B).

\section{Discussion}

Our findings point to distinct growth blocking properties of VPA on colon tumor cells in vitro and in vivo, which are in accordance with previous reports that HDAC inhibition triggers growth inhibition of colon cancer cell lines alone or in combination with other drugs $(10,11)$. Of note, the antiproliferative effect of VPA in vivo peaked between treatment days 17 and 21 . Thereafter, the treatment effect subsided slightly as 
tumor growth increased again at day 24 of the administration period. The anti-neoplastic properties of VPA were found to be dependent on its exposure time in a kidney cancer cell model (5). Moreover, the results of clinical studies on VPA in the context of anti-neoplastic therapy suggest that chronic application of the drug is required (12). Nevertheless, in light of the finding that our in vivo model partially regained its growth capability under VPA treatment, the potential of VPA to induce resistance in colon cancer cells must be taken into consideration (13).

Since VPA is a known HDAC inhibitor, it was of interest to monitor the alterations of histone acetylation in our models. High expression of HDAC class I has previously been described as a possible treatment target and a prognostic factor in colorectal cancer cells (14). Additionally, it has been shown that the HDAC inhibitory properties of VPA are essential for its anti-neoplastic activity (15). Therefore, it is of relevance to note that histone acetylation increased significantly in our in vitro and in vivo models. Among the cell cultures, SW-480 exhibited the strongest acetylation response of $\mathrm{H} 3$ and $\mathrm{H} 4$ in comparison to the other cell lines. This finding, together with the previously described strong expression of HDAC in these cells (16), contributed to the choice of SW-480 for the in vivo experiments. High levels of HDAC3 expression in SW-480 cells correlated with a strong response to HDAC inhibition through VPA treatment (17). A substantial increase in acetylation under VPA treatment was observed in our SW-480 xenografts, although a certain degree of acetylation was already prominent in the control animals. Taken together, the findings suggest that VPA exhibits its anti-neoplastic effect in colorectal cancer cell lines through alteration of histone acetylation.

In concordance with previously published results, cell cycle analysis revealed a shift towards the G0/G1 phase under the influence of VPA, with gradual differences in the investigated tumor cells. The corresponding Western blot analysis of crucial cell cycle regulating proteins revealed that only cdk1 expression was uniformly decreased by VPA in all of the cell lines. We therefore postulate that this mechanism is (at least partially) responsible for the cell cycle delay and growth blockade. In this context, VPA at a high dose of $300 \mathrm{mg} / \mathrm{kg}$ applied in vivo triggered a slight increase in cdk1 expression compared to the $200 \mathrm{mg} / \mathrm{kg}$ dose. The reversal of cdk1 response with high VPA doses may contribute to the corresponding impairment of VPA-induced growth reduction. Based on the SW-480 results, cdk2 does not appear to play a role in the context of VPA-induced cell cycle changes. This can be valued in light of the fact that cdk2 is dispensable for $\mathrm{S}$ phase initiation as shown in cdk2 knockout studies (18). Regarding cdk4, it is of note that Caco-2 and CX-1 cells responded with down-regulation, and SW-480 and WIDR with the opposite phenomenon. Since the deregulation of the cyclin D/cdk4 pathway has been identified as a feature of multiple tumor types contributing to their growth advantage (19), this finding would not have been expected.

Furthermore, it is unclear why cyclin E showed decreased expression solely in Caco-2 cells, while the other cell lines and the in vivo tumors displayed an increase in its expression. The fact that cyclin E-deficient mice develop normally (20) may aid in the assessment of the role of cyclin $\mathrm{E}$ in the anti- neoplastic effect of VPA. Cyclin D1 is of interest regarding the mitogenic potential of the analyzed cell lines. Cyclin D1 is overexpressed in a number of cancers (21) and additionally its repression promotes cellular differentiation (22). Consequently, the suppression of cyclin D1 may be relevant for maintaining cellular quiescence and preventing cell proliferation (23).

In this context, HDAC1 has been described to participate in a complex that inhibits the cyclin D1 promotor (24). Therefore, cyclin D1 may be an ideal target of VPA activity, and its subsequent suppression under VPA treatment would be expected. However, this held true only for Caco-2 and CX-1 cells. This again underlines the variability of cellular events initiated by VPA. Although growth repression and reduced cell cycle activity were present in all four cell lines, this cannot be stringently connected with uniform alterations of cell cycle-regulating proteins. However, it is possible that the observed increases in cell cycle proteins are initiated to counteract the antiproliferative effect of VPA, thereby maintaining mitogen requirements to uphold cellular proliferation (25). Since these changes were also observed in the in vivo model, we hypothesize that the up-regulation of cyclins contributed to the recovery of tumor growth after VPA treatment at day 21 as the tumor becomes adjusted to the anti-neoplastic effect of VPA (13).

The second group of proteins that impact cell proliferation are tumor suppressors or cyclin-dependent kinase inhibitors. We investigated p19, p21 and p27. While p19 was not altered, p21 and p27 were increased in all cell lines. The in vivo situation differed somewhat with constant expression of p21 and increased expression of $\mathrm{p} 19$ and $\mathrm{p} 27$ in the SW-480 xenograft tumors under VPA treatment. In light of these observations it is evident that all three tumor-suppressor proteins were involved in the anti-neoplastic effect of VPA in the colon cancer cell lines. p19 has been shown to promote cell cycle arrest or apoptosis via p53 degradation (26). As a member of the INK4 protein group, it inhibits the catalytic subunits of cdk4 and cdk6 (25). Examples for P19 involvement in HDAC inhibitor activity are scarce. Trichostatin A and sodium butyrate up-regulated p19 in murine fibroblasts, while fibrosarcomas in ARF knockout mice were more resistant to HDAC inhibitor treatment (27). Notably, the in vivo model exhibited a slightly reduced p19 and p27 induction when treated with $300 \mathrm{mg} / \mathrm{kg}$ VPA. This finding may have contributed to the reduced effectiveness of the higher dose against tumor growth when compared to $200 \mathrm{mg} / \mathrm{kg}$ of VPA.

p21, which was mostly induced by VPA application in our in vitro experiments, has already been established as a protagonist in the mode of VPA or HDAC inhibitor activity, respectively, and recently was confirmed in the treatment of rhabdomyosarcoma cells with VPA resulting in cell cycle arrest (28). A similar effect of VPA treatment with G2/M phase blockade caused by p21 activation has been shown for human mesenchymal stem cells (29). Moreover, HDAC4-induced growth of the colon cancer cell line HCT 116 appeared to be dependent on $\mathrm{p} 21$, since its absence abrogated the growth response (30). p27 belongs to a more broadly acting Cip/ Kip protein family which is able to inhibit cyclin D-, E- and A-dependent kinases (31). Thereby, it carries the capability to inhibit the progression from $\mathrm{G} 1$ to $\mathrm{S}$ phase (cyclin E-dependent) 
and S phase progression (cyclin A-dependent) (32). Our results of up-regulation of $\mathrm{p} 27$ in both the in vivo and in vitro model are in agreement with a number of reports, which have documented p27 involvement with VPA treatment and G0/G1 phase arrest (33).

Significant induction of apoptosis in vitro was recorded only at the highest VPA concentrations. Although apoptosis is an established process involved in the anti-neoplastic mechanisms of VPA, we assume that it does not play a predominant role in our experimental setup and the investigated cell lines. Similar results have been described for cultured thoracic cancer cells, where VPA induced apoptosis in less than $20 \%$ of the cells in culture (34), which corroborates our results.

Taken together, our findings contribute to the understanding of VPA-associated anti-neoplastic effects. VPA exhibited a robust growth inhibition of colorectal cancer cell lines in the in vitro and in vivo models mainly by modification of the cell cycle and corresponding regulating proteins. We suggest that VPA may become an innovative option for the treatment of colorectal malignancies, since VPA is a clinically established drug with few side effects (12). Nevertheless, a number of questions have yet to be answered. The regain of tumor growth after a longer VPA treatment period challenges the concepts of long-term VPA application to inhibit tumor progression. Perhaps combination therapy with other cytotoxic agents could come into play.

\section{References}

1. Taunton J, Hassig CA and Schreiber SL: A mammalian histone deacetylase related to the yeast transcriptional regulator Rpd3p. Science 272: 408-411, 1996.

2. Gurvich N, Tsygankova OM, Meinkoth JL and Klein PS: Histone deacetylase is a target of valproic acid-mediated cellular differentiation. Cancer Res 64: 1079-1086, 2004.

3. Gottlicher M, Minucci S, Zhu P, et al: Valproic acid defines a novel class of HDAC inhibitors inducing differentiation of transformed cells. EMBO J 20: 6969-6978, 2001.

4. Kuendgen A and Gattermann N: Valproic acid for the treatment of myeloid malignancies. Cancer 110: 943-954, 2007.

5. Jones J, Juengel E, Mickuckyte A, Hudak L, Wedel S, Jonas D and Blaheta RA: The histone deacetylase inhibitor valproic acid alters growth properties of renal cell carcinoma in vitro and in vivo. J Cell Mol Med 13: 2376-2385, 2009.

6. Tan J, Cang S, Ma Y, Petrillo RL and Liu D: Novel histone deacetylase inhibitors in clinical trials as anti-cancer agents. J Hematol Oncol 3: 5, 2010.

7. Lea MA, Ibeh C, Shah N and Moyer MP: Induction of differentiation of colon cancer cells by combined inhibition of kinases and histone deacetylase. Anticancer Res 27: 741-748, 2007.

8. Huang X and Guo B: Adenomatous polyposis coli determines sensitivity to histone deacetylase inhibitor-induced apoptosis in colon cancer cells. Cancer Res 66: 9245-9251, 2006

9. Friedmann I, Atmaca A, Chow KU, Jager E and Weidmann E: Synergistic effects of valproic acid and mitomycin C in adenocarcinoma cell lines and fresh tumor cells of patients with colon cancer. J Chemother 18: 415-420, 2006.

10. Biran A, Brownstein M, Haklai R and Kloog Y: Downregulation of survivin and aurora A by histone deacetylase and RAS inhibitors: a new drug combination for cancer therapy. Int J Cancer 128: 691-701, 2011.

11. Koyama M, Izutani Y, Goda AE, et al: Histone deacetylase inhibitors and 15-deoxy-Delta12,14-prostaglandin J2 synergistically induce apoptosis. Clin Cancer Res 16: 2320-2332, 2010

12. Muller S and Kramer OH: Inhibitors of HDACs - effective drugs against cancer? Curr Cancer Drug Targets 10: 210-228, 2010

13. Fedier A, Dedes KJ, Imesch P, von Bueren AO and Fink D: The histone deacetylase inhibitors suberoylanilide hydroxamic (Vorinostat) and valproic acid induce irreversible and MDR1independent resistance in human colon cancer cells. Int J Oncol 31: 633-641, 2007
14. Weichert W, Roske A, Niesporek S, et al: Class I histone deacetylase expression has independent prognostic impact in human colorectal cancer: specific role of class I histone deacetylases in vitro and in vivo. Clin Cancer Res 14: 1669-1677, 2008.

15. Venkataramani V, Rossner C, Iffland L, et al: Histone deacetylase inhibitor valproic acid inhibits cancer cell proliferation via down-regulation of the Alzheimer amyloid precursor protein. J Biol Chem 285: 10678-10689, 2010.

16. Spurling CC, Godman CA, Noonan EJ, Rasmussen TP, Rosenberg DW and Giardina C: HDAC3 overexpression and colon cancer cell proliferation and differentiation. Mol Carcinog 47: 137-147, 2008.

17. Chavez-Blanco A, Perez-Plasencia C, Perez-Cardenas E, et al: Antineoplastic effects of the DNA methylation inhibitor hydralazine and the histone deacetylase inhibitor valproic acid in cancer cell lines. Cancer Cell Int 6: 2, 2006.

18. Satyanarayana A and Kaldis P: Mammalian cell-cycle regulation: several Cdks, numerous cyclins and diverse compensatory mechanisms. Oncogene 28: 2925-2939, 2009.

19. Liu N, Fang H, Li Y and Xu W: Recent research in selective cyclin-dependent kinase 4 inhibitors for anti-cancer treatment. Curr Med Chem 16: 4869-4888, 2009.

20. Hanashiro K, Kanai M, Geng Y, Sicinski P and Fukasawa K: Roles of cyclins $\mathrm{A}$ and $\mathrm{E}$ in induction of centrosome amplification in p53-compromised cells. Oncogene 27: 5288-5302, 2008.

21. Yamamoto M, Tamakawa S, Yoshie M, Yaginuma $Y$ and Ogawa K: Neoplastic hepatocyte growth associated with cyclin D1 redistribution from the cytoplasm to the nucleus in mouse hepatocarcinogenesis. Mol Carcinog 45: 901-913, 2006.

22. Mejlvang J, Kriajevska M, Vandewalle C, et al: Direct repression of cyclin D1 by SIP1 attenuates cell cycle progression in cells undergoing an epithelial mesenchymal transition. Mol Biol Cell 18: 4615-4624, 2007.

23. Klein EA and Assoian RK: Transcriptional regulation of the cyclin D1 gene at a glance. J Cell Sci 121: 3853-3857, 2008.

24. Rampalli S, Pavithra L, Bhatt A, Kundu TK and Chattopadhyay S: Tumor suppressor SMAR1 mediates cyclin D1 repression by recruitment of the SIN3/histone deacetylase 1 complex. Mol Cell Biol 25: 8415-8429, 2005.

25. Sherr CJ and Roberts JM: CDK inhibitors: positive and negative regulators of G1-phase progression. Genes Dev 13: 1501-1512, 1999.

26. Weber HO, Samuel T, Rauch P and Funk JO: Human p14 (ARF)mediated cell cycle arrest strictly depends on intact p53 signaling pathways. Oncogene 21: 3207-3212, 2002.

27. Matheu A, Klatt P and Serrano M: Regulation of the INK4a/ ARF locus by histone deacetylase inhibitors. J Biol Chem 280: 42433-42441, 2005.

28. Hecker RM, Amstutz RA, Wachtel M, Walter D, Niggli FK and Schafer BW: p21 Downregulation is an important component of PAX3/FKHR oncogenicity and its reactivation by HDAC inhibitors enhances combination treatment. Oncogene 29: 3942-3952, 2010.

29. Lee S, Park JR, Seo MS, et al: Histone deacetylase inhibitors decrease proliferation potential and multilineage differentiation capability of human mesenchymal stem cells. Cell Prolif 42: 711-720, 2009.

30. Wilson AJ, Byun DS, Nasser S, et al: HDAC4 promotes growth of colon cancer cells via repression of p21. Mol Biol Cell 19: 4062-4075, 2008.

31. Toyoshima $\mathrm{H}$ and Hunter $\mathrm{T}$ : $\mathrm{p} 27$, a novel inhibitor of $\mathrm{G} 1$ cyclin-Cdk protein kinase activity, is related to p21. Cell 78: 67-74, 1994.

32. Edgar BA and Orr-Weaver TL: Endoreplication cell cycles: more for less. Cell 105: 297-306, 2001

33. Freidkin I, Herman M, Tobar A, Chagnac A, Ori Y, Korzets A and Gafter U: Effects of histone deacetylase inhibitors on rat mesangial cells. Am J Physiol Renal Physiol 298: F426-F434, 2010.

34. Ziauddin MF, Yeow WS, Maxhimer JB, et al: Valproic acid, an antiepileptic drug with histone deacetylase inhibitory activity, potentiates the cytotoxic effect of Apo2L/TRAIL on cultured thoracic cancer cells through mitochondria-dependent caspase activation. Neoplasia 8: 446-457, 2006. 